\title{
Mirando a través de las ventanas digitales
}

\section{Looking through digital windows}

\author{
TIPO DE TRABAJO: Comunicación.
}

\author{
PALABRAS CLAVE
}

Pantalla, digital, mirada, código, materia.

\section{KEY WORDS}

Screen, digital, gaze code, matter.

\section{RESUMEN}

A lo largo de la historia, ha habido una constante preocupación por representar la realidad mediante imágenes, haciendo visible lo estrictamente mental y/o sensorial. La necesidad por plasmar la apariencia de lo real, originó la fabricación de ventanas y aparatos ópticos basados en la perspectiva o proyección de un espacio real concreto, para poder materializar con exactitud la imagen sobre un soporte que la contuviera.

Esta imagen convertida en objeto, lleva implícito el hecho de estar encuadrada dentro de un área, un fragmento de lo que se percibe a través del ojo humano, mostrando al espectador lo que el artífice de dicha imagen ha decidido, delimitando al observador a ver un determinado espacio de la realidad.

De un tiempo a esta parte, con la llegada de las nuevas tecnologías digitales, estamos constantemente envueltos de delimitadores de imágenes. Vemos el mundo a través de pantallas que generan sus propios códigos mostrando una realidad virtual, una apariencia digital.

En la práctica artística de esta investigación, especialmente la pantalla del ordenador y el escáner, entre otros dispositivos de registro, son los principales responsables para generar o captar imágenes, creando su propia realidad, sin la necesidad de la intervención del ojo humano. Las imágenes generadas por estos dispositivos y contenidas en forma de archivo, solo pueden ser mostradas por las propias máquinas capaces de codificar su lenguaje y traducirlo en forma de pixel, provistas de luz para poder ser percibido por nuestro órgano visual.

Es por eso que, esta premisa nos hace reflexionar sobre la necesidad de materializar la imagen sobre un soporte, como un ejercicio de memoria y de visibilidad, como algo que perdura en el tiempo y que ha de ser extraído de su lugar de origen. Esta última idea está ligada con el concepto de transferencia: la acción de transportar a la imagen de un lugar a otro, para asentarse definitivamente en un soporte que otorgue de corporeidad a la imagen digital.

\section{ABSTRACT}

Throughout history, there has been a constant concern to represent reality through images, making the strictly mental and / or sensory visible. The need to capture the appearance of the real, originated the manufacture of windows and optical devices based on the perspective or projection of a concrete real space, in order to accurately materialize the image on a support that contained it.

This image turned into an object, implies the fact of being framed within an area, a fragment of what is perceived through the human eye, showing the viewer what the architect of said image has decided, delimiting the observer to see a determined space of reality. 
For a while now, with the arrival of new digital technologies, we are constantly surrounded by image delimiters. We see the world through screens that generate their own codes showing a virtual reality, a digital appearance.

In the artistic practice of this research, especially the computer screen and the scanner, among other recording devices, are the main responsible for generating or capturing images, creating their own reality, without the need for the intervention of the human eye. The images generated by these devices and contained in file form, can only be shown by the machines themselves capable of coding their language and translate it into a pixel, provided with light to be perceived by our visual organ.

That is why, this premise makes us reflect on the need to materialize the image on a support, as an exercise of memory and visibility, as something that lasts over time and that has to be extracted from its place of origin. This last idea is linked to the concept of transfer: the action of transporting the image from one place to another, to settle definitively in a support that gives corporeality to the digital image.

\section{INTRODUCCIÓN}

El interés por representar la realidad a través de las imágenes ha sido uno de los objetivos principales en el ámbito artístico. Desde el renacimiento con la creación de artilugios y el estudio de la perspectiva, pasando por la fotografía hasta llegar a nuestros tiempos con tecnología que es capaz de generar y producir imágenes por ella misma.

Este desarrollo tecnológico ha sido el responsable de otorgar un cambio de paradigma al pensamiento primigenio del uso y desarrollo de las imágenes, transformando nuestra manera ver, ahora, a través de pantallas que generan una serie de códigos capaces de ser traducidos para poder percibirlos por nuestra visión.

La tecnología digital está presente hoy día en los estudios y talleres de cualquier artista, formando parte de nuestras herramientas de trabajo, tanto que hemos dotado de autonomía a la propia máquina, capaz de generar obra original. Hemos pasado de mirar a través de ventanas como la de Alberti o Leonardo, a dejar que las máquinas miren por nosotros e interpreten su propia realidad, para ser mostradas en ventanas conformadas por pixeles y luz.

\section{METODOLOGÍA}

El presente articulo presenta algunas de las conclusiones extraídas de la Tesis Doctoral en proceso titulada Procesos de transferencia con tecnologías de impresión inkjet para la creación artística digital dentro del programa de doctorado Arte: Producción e Investigación. En concreto para este artículo, se expone la parte donde la mirada es el origen para la creación y posterior materialización a través de las diferentes ventanas y pantallas que surgen a lo largo de la historia.

Para su construcción se ha seguido dos vertientes que se diferencian por la parte teórica y de recopilación de datos mediante documentación extraída de fuentes literarias como ensayos, tesis o libros referentes al tema que acontece, así como la selección de artistas pertinentes que reflexionan sobre las nuevas tecnologías aplicadas en el campo artístico.

El segundo de los recursos metodológicos utilizados es la práctica, en donde la propia autora realiza una investigación y exploración sobre los diferentes procesos plásticos para llevar a cabo la transferencia de imágenes emanadas de las impresoras de inyección de tinta, partiendo del escáner como ventana para generar las imágenes digitales.

Como punto de partida, se pone en contexto al lector acerca del surgimiento de las diferentes ventanas para mirar hasta llegar a la actualidad con las ventanas digitales, las pantallas actuales. Seguidamente, las influencias de los diferentes artistas referentes en cada una de las épocas y finalmente la aportación de obra artística propia concluyendo la investigación.

Rubén Tortosa (2011: 42) escribe "Ya no consiste solo en ser digitales, sino analizar el tránsito de lo analógico/digital y lo digital/analógico como flujos de procesos caracterizados por la hibridación de entornos físicos y virtuales." 


\section{DESARROLLO}

Esta inquietud por experimentar a través de las imágenes la realidad que nos envuelve ya la planteó Platón, cuando, a través de aquellas sombras proyectadas en la cueva, hacía creer a los hombres de que se trataba de un ente real y no de una iconografía que reproducía el objeto real. Esta experiencia de lo sensible ha sido el principal punto de exploración para muchos artistas. Román Gubern (1996: 8) escribe: “Como ya avanzó Platón, pues quiere hacer creer al observador colocado ante la imagen que está en realidad ante su referente y no ante su copia".

El Renacimiento supuso una revolución tanto científica como tecnológica para el ámbito de las artes, especialmente en la creación de aparatos ópticos, los cuales facilitaban la labor a la hora de materializar sobre el soporte lo que se contemplaba. La preocupación por representar la realidad dio lugar a instrumentos que cambiaron la forma de mirar como el velo de Alberti o el perspectográfo de Leonardo. En ese momento, se miraba a través de ventanas, artilugios que se interponían de forma paralela entre el observador y el objeto. A partir de este periodo, la incansable exploración de instrumentos para ver dio lugar a nuevos inventos como la cámara oscura, y, ya en el siglo XVIII, gracias a los avances químicos de la época, se descubrió que ocurría una reacción de la luz en las sales de plata, dando paso a la fotografía, una manera de reproducir la realidad sin necesidad de pasar por el dibujo manual.

La fotografía cambió nuestra forma de ver y de concebir las imágenes, fragmentando el espacio que se capturaba y multiplicándolo para alcanzar a un público más extenso. Como señala José Ramón Alcalá (2011: 27) "el heredero artístico de las técnicas de reproducción, impresión y estampación" un proceso de reproducción de imágenes más eficaz. Walter Benjamin apunta (2003: 40) "el ojo capta más rápido de lo que la mano dibuja".

Evolucionada la técnica de procesos fotográficos y fotomecánicos, artistas del siglo XX, en medio de un paradigma social y cultural de consumo e inmediatez, empezaron a crear con técnicas serigráficas o litográficas. Con ello, empezó la exploración con las tecnologías de reproducción y generación de imágenes automáticas, la fotocopiadora. Una máquina destinada a la multiplicación de documentos, pero que para muchos artistas se postuló como una herramienta capaz de ofrecer nuevos puntos de vista instantáneos en la práctica artística con altas posibilidades creativas. Beatriz Escribano (2016: 37) señala que "por primera vez el artista pulsa un botón y se obtiene una imagen en tiempo real sin necesidad alguna de intermediarios ni procesos de postproducción". El potencial de estas máquinas quedo demostrado en el trabajo de Sonia L. Sheridan, quien fue una de las primeras artistas que exploró esta herramienta con una intención estética.

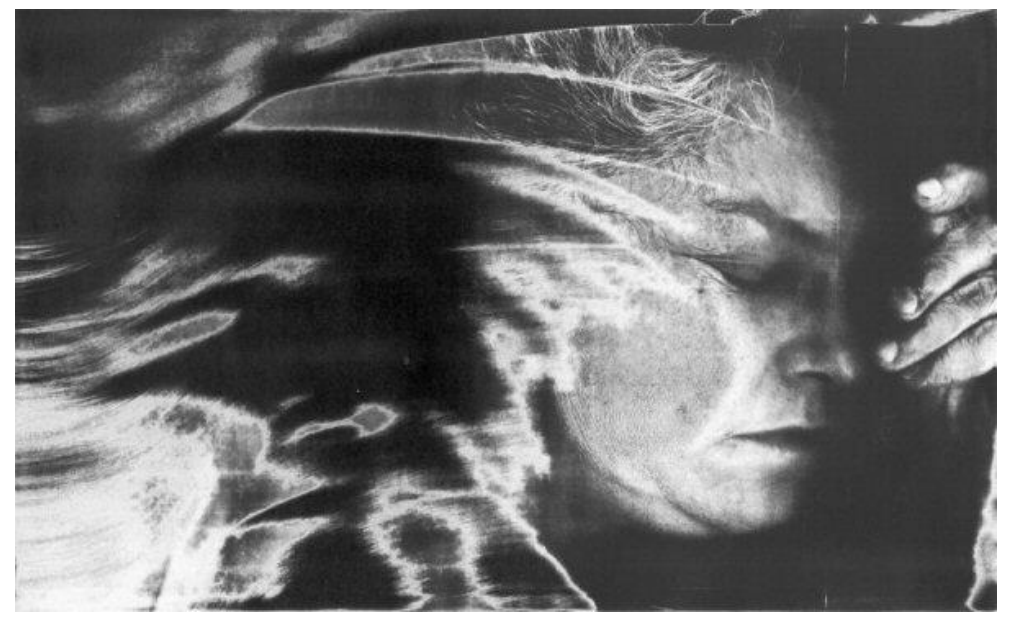

Figura 1: "Leyering, Stretching and Compressing Sonia in Time", Sonia Landy Sheridan, 1974. Fuente (http://www.fondation-langlois.org, (C) 2008 FDL)

La ventana por la que se mira en este momento pasa por un plano horizontal, donde se ejecuta un proceso que da vida a la imagen. El registro cambia de posición y con ello la manera de trabajar del artista, desde el plano de representación vertical al horizontal, depositando objetos sobre la pantalla, interactuando con la propia máquina, desquitándonos de la distancia técnica de producir una imagen con la cámara, pues ahora ya no estamos detrás del "ojo mecánico", como lo nombra John Berger (2000: 24), ahora estamos sobre el ojo mecánico de la máquina.) "Una nueva forma de tratar y producir imágenes con su lenguaje autónomo", como menciona (Rubén Tortosa (2004: 26). Esto quedó patente cuando el artista alemán Jürgen O. Olbrich realizó una pieza performativa donde bailaba un rock'n roll sobre la pantalla de la fotocopiadora, y cuyo resultado fueron las electrografías que mostraban las huellas de sus zapatos. No se trataba de copias sino de espacios temporales que registraban la acción. 


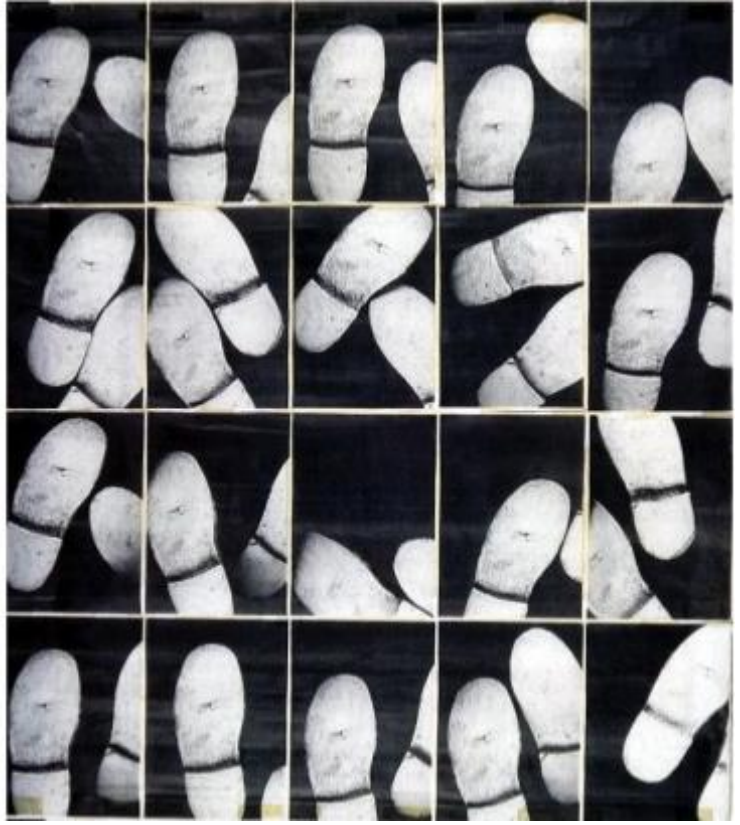

Figura 2: Jürgen O. Olbrich, Photo Copy Rock'n Roll, 1984. Fuente (Escribano, 2016). @MIDECIANT

La relación entre el artista y la máquina propició una nueva concepción de la obra artística como fin de un proceso de elaboración práctica. Ahora lo que preocupa no es la obra en sí, sino todo el proceso que se gesta para conseguir la impresión de esa imagen. La experimentación y la interactuación con las ventanas de las fotocopiadoras originó toda clase de intervenciones artísticas, pasando por el simple hecho de asomar algún objeto a la pantalla e imprimirlo multitud de veces, hasta la propia experimentación directa con el cuerpo, desmembrando o presentando variaciones físicas. Como señala Rubén Tortosa (2011: 36) "El proceso creativo y vital se integran diluyendo las limitaciones entre resultados y creación". La manera de visibilizar dicho acontecimiento solo podía ser a través de la impresión de las imágenes generadas, electrografías que se materializan en la superficie del papel, sin el cual no pueden darse. Obteniendo resultados delimitados por la propia morfología del espacio capturador del aparato y del propio soporte. La imagen concreta se aleja de composiciones equilibradas e imágenes nítidas, lo único que importa es hacer constar el suceso, no importa su imperfección.

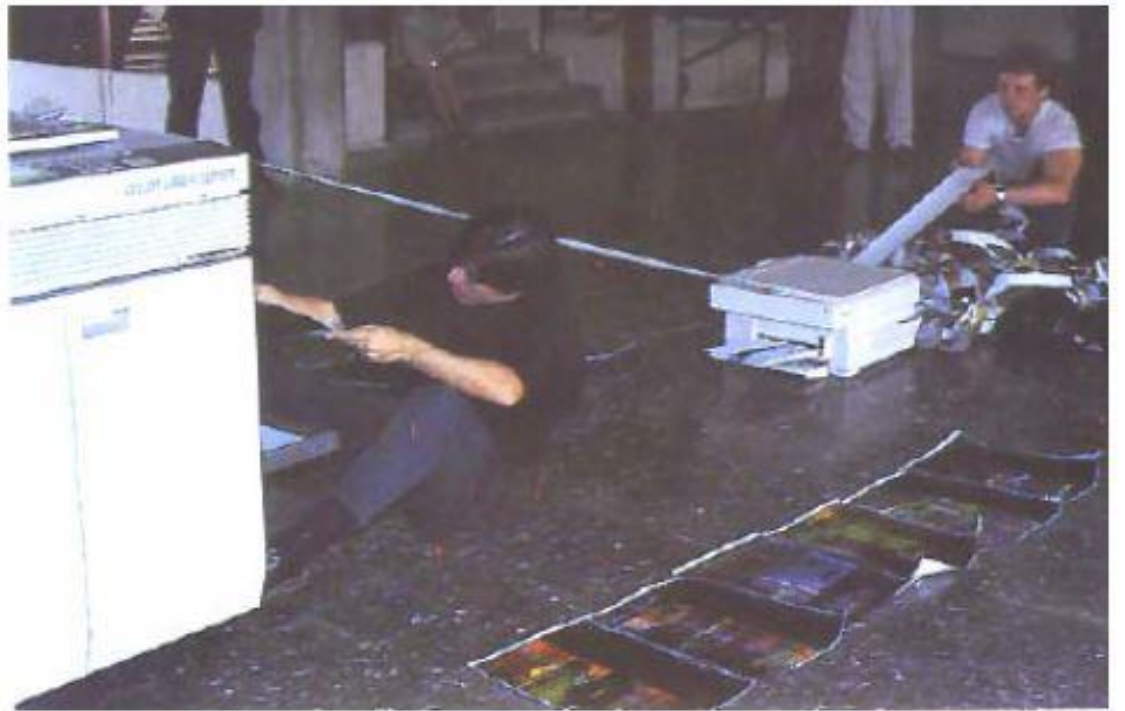

Figura 3: II Bienal Internacional de Electrografía y Copy Art, Performance ideada por Jürgen $O$. Olbrich y ejecutada con la colaboración de Rubén Tortosa. Valencia, 1988. Fuente (Tortosa, 2004), 
Con la tecnología digital, la constatación del suceso acontecido varía y por tanto la visibilidad de las imágenes. La imagen convertida en materia ya no es necesaria para poder ser visualizada. Las pantallas de los ordenadores ahora son las encargadas de hacer evidente aquello que registramos por medio del escáner o que generamos mediante softwares. La imagen digital es intangible, no se necesita el acercamiento físico para ser contempladas. Se constituyen por medio de códigos binarios que se traducen para ser vistos mediante la pantalla, la ventana digital que nos conduce a una realidad virtual. Como apunta José Ramón Alcalá (2011: 40) "la interpretación del mundo se realiza hoy a través de una interfaz basada en el poder metafórico de la pantalla y su espacio proyectivo eléctricamente infinito".

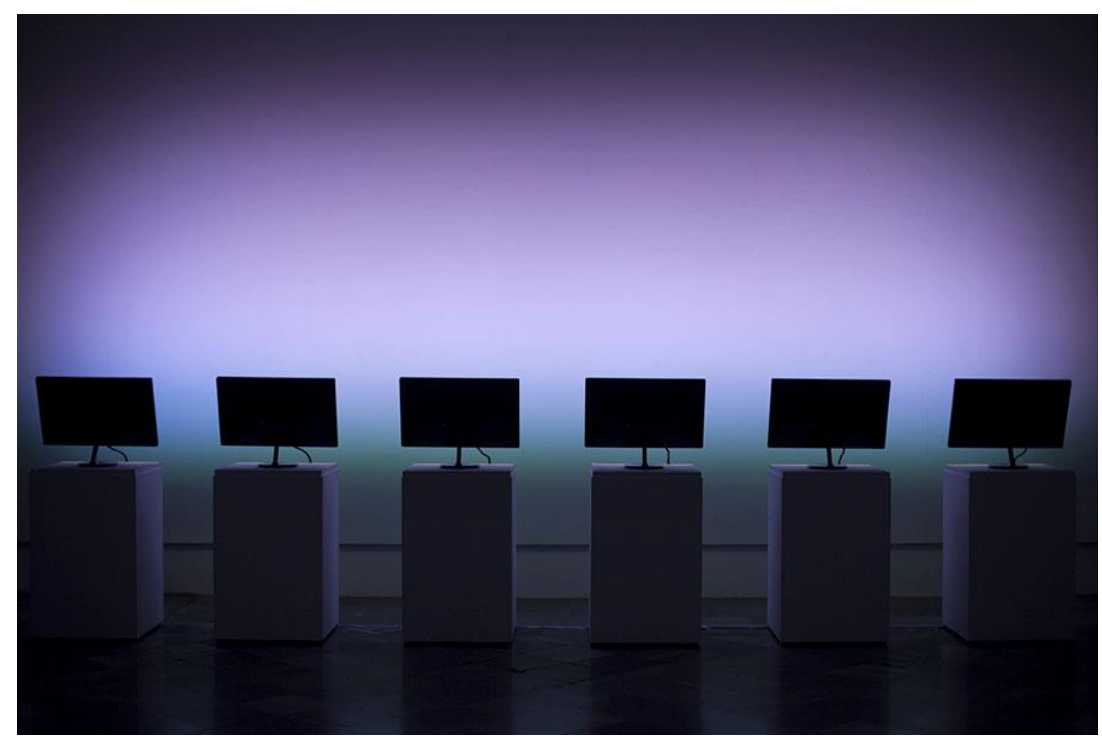

Figura 4: Inma Femenía Spectrum Screensaver 2014. Fuente https://inmafemenia.com

En la pieza de Inma Femenía Spectrum Screensaver (2014), según palabras de la propia artista "pone de manifiesto fenómenos lumínicos digitales con los que convivimos diariamente y que ya hemos naturalizado, como son el movimiento y las luces características de los salvapantallas de ordenador; imágenes que aparecen y desaparecen, creadas para activarse cuando llevamos un rato sin manipular nuestros teclados."

La reproducción de las imágenes no solo trascendió como una forma de inmediata de multiplicar, sino también en el modo de grabar esas imágenes sobre un soporte. Esto conllevó un cambio de nomenclaturas en lo que el mundo grafico que se refiere. La matriz donde se incide para obtener la huella deja de ser corpórea y pasa a ser una matriz intangible tan versátil que es capaz de estar sometida a manipulaciones para alcanzar la imagen deseada. Estas imágenes son guardadas en forma de archivo en la memoria del ordenador a la espera de su extracción. El tiempo y espacio de la imagen ocurrida queda suspendida en la interfaz del ordenador para que, en palabras de José Luis Brea (2010: 13), "pueda de nuevo recuperarse, venir de nuevo a ocurrir".

Pero en esta inmersión digital la necesidad por traducir lo intangible a físico provoca un movimiento nómada, en donde la imagen se desplaza, ocurriendo una transferencia de códigos que van siendo traducidos por el propio sistema. Este transferir no es solo un modo conceptual de definir lo que ocurre en el circuito de la imagen, "la transferencia: se transportan datos o signos de un punto a otro, y este gesto expresa nuestra época mejor que cualquier otro", como señala Nicolas Bourriaud (2009: 157) sino también una práctica artística que va más allá del simple hecho de concretar una imagen en el soporte. La mirada se expande, abriendo camino a nuevos recursos estéticos, en donde la imagen se asienta en diferentes materiales que difieren del papel. Lo humano y vital vuelve a formar parte en este proceso, derivando la repetición mecánica propia de los sistemas de impresión, haciendo palpable y visible lo estrictamente digital. 


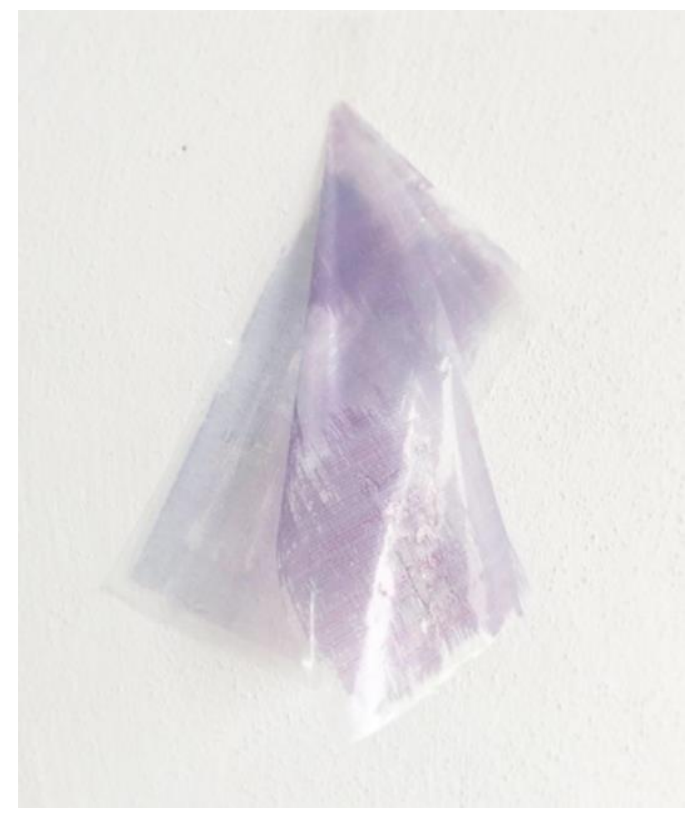

Figura 6: Claudia Molina Guixot, Sanner front Scanner, 2018.

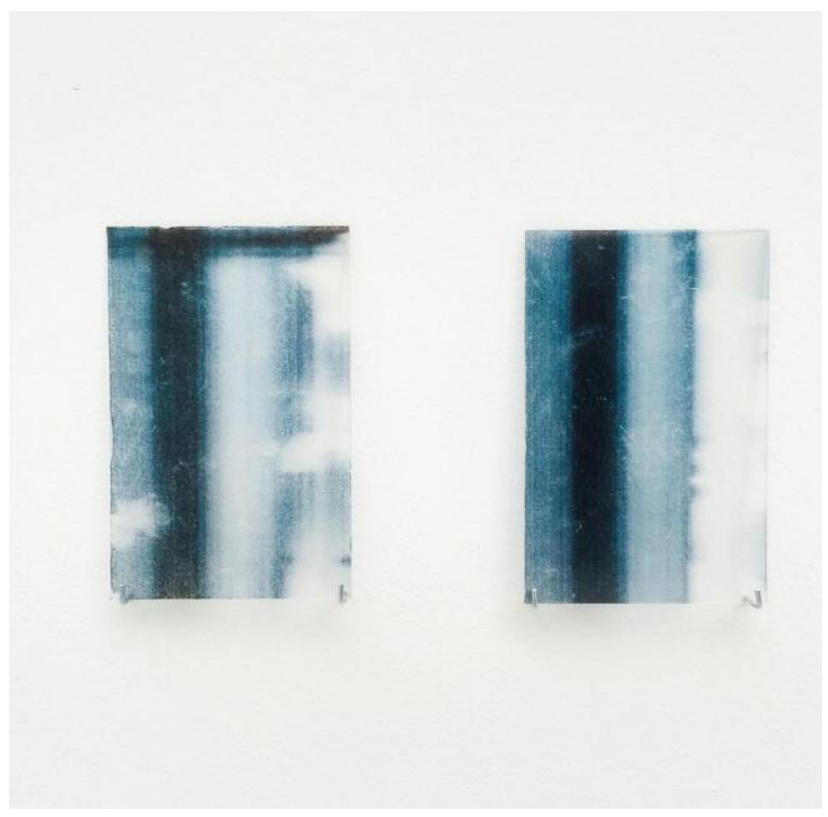

Figura 5: Claudia Molina Guixot, Sin Título, 2018.
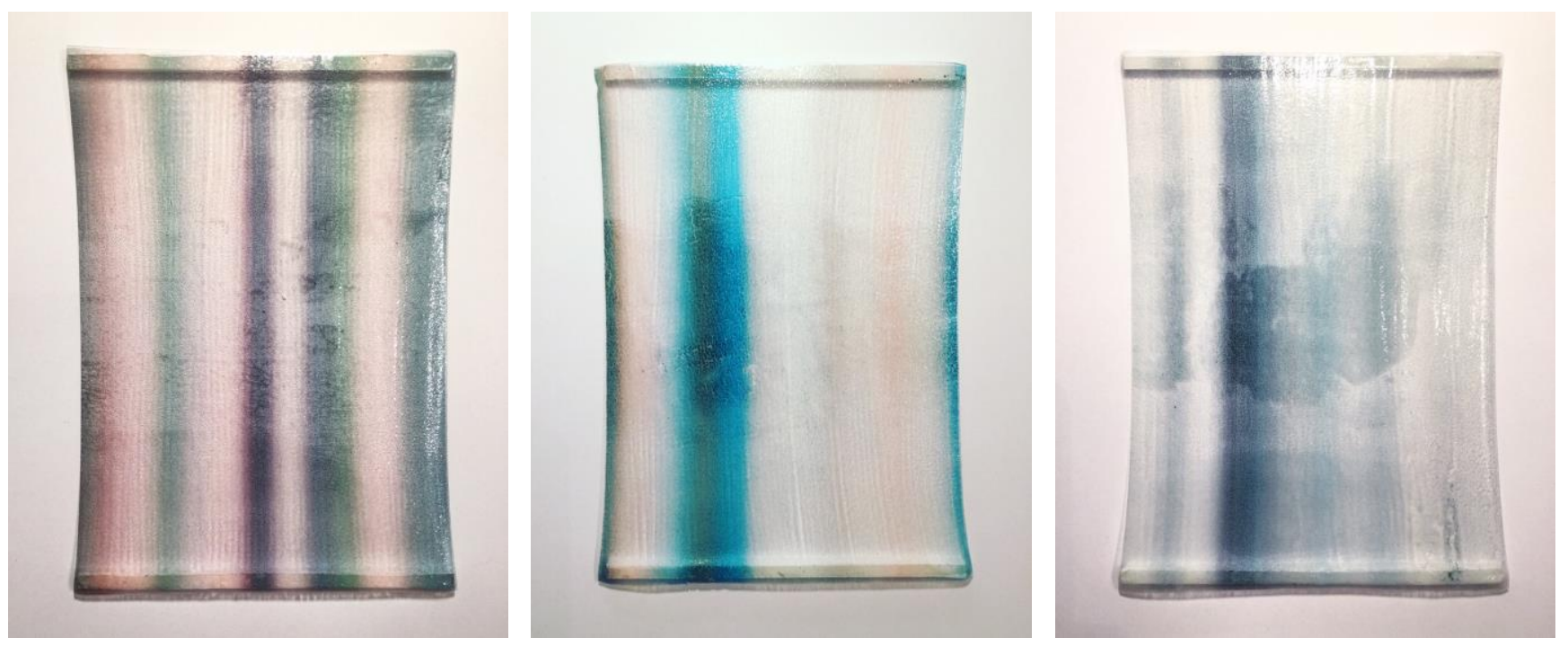

Figura 7, 8 y 9: Claudia Molina Guixot, de la serie Satellite Colors, 2018. 


\section{CONCLUSIONES}

La hibridación de los diferentes interlocutores humano y tecnológico ha provocado un nuevo lenguaje artístico, expandiendo la imagen más allá de un elemento de representación de la realidad, en donde la propia configuración de las máquinas ha ido conformando todo un imaginario, ampliando las barreras de nuestra óptica.

Atraídos por la autonomía y el comportamiento de la ventana del escáner, hemos dejado que ocurran cosas que se codifican para ser mostrado mediante la pantalla del ordenador, a la espera de descubrir lo que ha acontecido en el plano. Como si de rayogramas de trataran, como ya realizara Man Ray exponiendo sobre el papel fotosensible objetos que quedaban plasmados gracias a la exposición de la luz. Una luz que ahora forma parte del circuito electrónico del escáner, barriendo la superficie plana de la ventana de registro.

El funcionamiento ha cambiado, pero la esencia persiste, la obtención de la imagen es todo un hallazgo, ahora digital, permitiéndonos modificar aquello que hemos capturado, guardado, archivado para volverlo a modificar, obteniendo nuevas imágenes y perdiendo su origen. "Ese paso de un código a otro, funda, en las obras contemporáneas, una visión original del espacio-tiempo que cuestiona fuertemente las nociones de origen y de originalidad: la digitalización atenúa la presencia de la fuente, cada generación de imagen sólo representa un mero instante en una cadena sin principio ni fin." (Bourriaud, 2009: 157)

Pero para perdurar en el tiempo de forma estática hay que extraerlo, traduciendo el pixel en materia. La impresora, en nuestro caso de inyección de tinta, traslada y conforma la imagen en gotas que se ordenan para aparentar el aspecto que la pantalla nos ha mostrado. Esto queda patente en las piezas artísticas que la autora presenta como experimentación práctica personal.

\section{FUENTES REFERENCIALES}

Alcalá, J.R. (2011). La piel de la imagen: Ensayos sobre gráfica en la cultura digital. Valencia: Sendemà Editorial.

Berger, J. (2000). Modos de Ver (2ª ed.). Barcelona: Ediciones Gustavo Gili.

Bourriaud, N. (2009). Radicante. Argentina: Editorial Lebenglik.

Brea, J.L. (2010). Las tres eras de la imagen: Imagen-materia, film, e-image. Madrid: Ediciones Akal.

Escribano, B, Alcalá, J.R., Tortosa, R., Soler, A. y Prints, L. (2016). Procesos: El Artista y la Máquina. Reflexiones en torno al Media Art histórico. Cuenca: Universidad de Castilla-La Mancha.

Gubern, R. (1996). Del bisonte a la realidad virtual: la escena y el laberinto (4aㅡ. ed.). Barcelona: Editorial Anagrama.

Pastor, J. y Alcalá J.R. (1997). Procedimientos de transferencia en la creación artística. Pontevedra: Diputación de Pontevedra.

Soler, A. y Castro, K. (Coords). Impresión piezoeléctrica: la estampa inyectada. Pontevedra: Universidad de Vigo.

Soler, A. y Castro, K. (Coords). Inter(medios): La matriz intangible. Pontevedra: Universidad de Vigo.

Tortosa, R. (2011). La mirada no retiniana: Huellas electrónicas desde el registro horizontal y su visualización mediante la impresión. Valencia: Sendemà Editorial.

Tortosa, R. (2004). Laboratorio de una mirada: Procesos de creación a través de tecnologías electrográficas. Tesis doctoral. Universidad Politécnica de Valencia.

Walter. B. (2003). La obra de arte en la época de su reproductibilidad técnica. México: Itaca. 